\title{
Crítica de la crítica a la sociología crítica a partir de Luc Boltanski
}

\section{Critique of the critique to critical sociology from Luc Boltanski}

Emiliano Gambarotta (emilianogambarotta@yahoo.com.ar) Consejo Nacional de Investigaciones Científicas y Técnicas (Buenos Aires, Argentina) http://orcid.org/0000-0002-8526-4819

\begin{abstract}
The article is inserted in a discussion about the way in which sociology problematizes culture, specifically, the paper analyses the modus operandi for a critical approach to the culture. For this, it focuses on the Luc Boltanski's proposal, because he makes the discussion on the "critical sociology" a central instance of his cultural study without abandoning the critical claim. With the goal of analysing these questions, the first section is dedicated to characterizing Boltanski's pragmatic sociology of critique. The second section argues that he proposes a powerful modus operandi for the sociological description of the actors' normativity, but that it does not solve the problems that would allow the critical research of that normativity. Topic that is developed through the discussion of his research on the "spirit of capitalism". Finally, the conclusions propose a path through which to advance towards this critical sociology, centred on the notions of ideology and utopia.
\end{abstract}

Key words: normativity, pluralism, neoliberalism, modus operandi, utopia.

\section{Resumen}

El artículo se inscribe en una discusión acerca del modo en que la sociología problematiza a la cultura, específicamente, se interroga por el modus operandi para un abordaje crítico de la misma. Para ello, se enfoca en la propuesta elaborada por Luc Boltanski, en tanto él hace del cuestionamiento a la "sociología crítica" una instancia central de su estudio de la cultura, sin por ello abandonar la pretensión crítica. Con vistas a analizar estas cuestiones, se dedica la primera sección a la caracterización de la sociología pragmática de la crítica de Boltanski. La segunda sección sostiene que él propone un potente modus operandi para la descripción sociológica de la normatividad de los actores, pero que no resuelve los problemas que posibilitarían el abordaje crítico de dicha normatividad. Punto que se profundiza a partir de la discusión de su investigación sobre el "espíritu del capitalismo". Finalmente, las conclusiones plantean un sendero por el cual avanzar hacia esa sociología crítica, con eje en la reproblematización de las nociones de ideología y utopía.

Palabras clave: normatividad, pluralismo, neoliberalismo, mouds operandi, utopía. 


\section{Introducción}

Este trabajo se inscribe en una discusión en torno a cómo la sociología problematiza la cultura, más específicamente, a su capacidad de abordarla críticamente. Cuestión atinente al método, en su viejo sentido de camino o, mejor aún, a aquello que con Pierre Bourdieu cabe llamar el modus operandi, el modo en que se configura la práctica de la sociología, en este caso, para producir un conocimiento crítico. Sobre este telón de fondo, puede percibirse el por qué aquí se sitúa el foco en la propuesta de Luc Boltanski, en tanto su perspectiva explícitamente cuestiona a la "sociología crítica", haciendo de ello un punto de partida de su propia perspectiva. Pero sin que esto conlleve un pleno abandono de la crítica, antes bien, él plantea su reelaboración, en el marco de una sociología pragmática. Dar cuenta de esos cuestionamientos de Boltanski, a la vez que se caracteriza a su sociología pragmática de la crítica, son, entonces, los ejes del presente artículo.

Boltanski elabora una versión propia de dos de las objeciones más recurrentes y relevantes que se le realizan a la sociología crítica: que se trata de una perspectiva que no puede acoger el pluralismo, en tanto la crítica no solo aborda a la cultura y sociedad actuales, sino también contiene una determinada orientación para el cambio, un "hacia dónde" transformar el presente, concretando una lógica que hoy no tiene lugar, en lo que puede denominarse su momento utópico. Pero esto puede llevar a tornar toda otra orientación en un camino que no conduce a la verdadera transformación del presente, antes bien, que contribuye a su reproducción. Así, se le niega legitimidad a toda orientación otra (a la propia), disolviendo la posibilidad que la perspectiva crítica acoja el pluralismo. Esto se plasma, ejemplarmente, en la noción de "falsa conciencia", en tanto la misma implica que la perspectiva crítica conoce cuáles son los verdaderos intereses de los actores y, por tanto, cuál debería ser la orientación de sus acciones, si no fuese porque tienen una visión falsa de sus propios intereses. Punto que se enlaza con el segundo cuestionamiento a la sociología crítica, según el cual ella no es capaz de dar cuenta de las competencias de los actores, al tender a reducirlos al solo producto de la dominación social, a cuya reproducción contribuirían sin más. Analizar cómo Boltanski retoma estas objeciones, junto con la manera en que propone sortearlas, es, entonces, la vía por la cual este escrito se interroga acerca del modus operandi de una sociología crítica.

\section{La normatividad sociológica}

En el núcleo de la perspectiva elaborada por Boltanski se encuentra la (re)problematización de una tensión central al pensamiento sociológico: la compleja relación entre el punto de vista del actor y el sociólogo(a). Tensión que en él adquiere en dos expresiones entrelazadas, pero analíticamente diferenciables: una atinente a la percepción de los actores y su relación con el conocimiento propiamente sociológico, la otra atinente a la apreciación, a cómo los actores juzgan su situación como justa o injusta, en una problemática de carácter moral. Así, Boltanski busca "proporcionar un nuevo impulso a un programa de investigación circunscripto al ámbito de la sociología moral" (Boltanski 2016:11). Ambas expresiones quedan reunidas en una problematización de la crítica, en tanto ésta implica poner en juego el conocimiento de la situación para producir un juicio acerca de su carácter (in)justo.

Pero la novedad del planteo de Boltanski reside en que su foco no está en la crítica que se realiza desde el punto de vista de la sociología, sino en aquella realizada por los actores, desde su específico punto de vista. Así, su proyecto de una sociología de la moral se específica en una sociología de la 
crítica, esto es, una sociología que toma como su específico objeto de estudio a "las operaciones críticas performadas por los actores" (Boltanski y Thévenot 1999:364), pues "los juicios morales que formulan los actores en el transcurso de sus actividades cotidianas adoptan muy a menudo la forma de críticas" (Boltanski 2014:18). Es por la vía de la capacidad crítica de los actores que Boltanski busca reproblematizar a la sociología crítica, la cual, entonces, realiza una "metacrítica", que ha de ser distinguida "de las múltiples tomas de posición críticas que adoptan las personas corrientes" (Boltanski 2014:22), en tanto aquella es una construcción teórica, "que tiende a realizar la crítica de un orden social aprehendido en su globalidad" (Boltanski 2014:22).

Este planteo entraña, por ende, dos problemas de método: uno orientado a aprehender la crítica de los actores corrientes, con vistas a "modelizar tanto la actividad de los actores como las competencias empleadas en el curso de las disputas" (Boltanski 2014:52). Se trata, en definitiva, de trazar un camino para modelizar el sentido (práctico o, mejor aún, pragmático) moral de los actores. A estos modelos Boltanski, junto con Thévenot, dan el nombre de ciudades (cités). El otro dirigido a problematizar la (meta)crítica realizada desde el punto de vista sociológico, interrogando, específicamente, cómo darle un fundamento, sin que ello acarree las dos objeciones ya señaladas: la disolución del pluralismo y la incapacidad de dar cuenta de las competencias de los actores.

Esto último toca un tema que atraviesa al conjunto de la práctica sociológica, en tanto su razón de ser es producir un conocimiento no inmediatamente accesible al punto de vista de los actores. "Y es que si la sustancia de su objeto resultara siempre evidente a los ojos de todos sucedería, sencillamente, que las ciencias sociales no tendrían ninguna razón de ser. Puede por tanto decirse, por esto mismo, que la sociología revela poseer, ya en su propia concepción, un carácter potencialmente crítico" (Boltanski 2014:25). Sin embargo, esto no ha de llevar a asumir "la existencia de una asimetría insuperable entre un agente social que se llama a engaño y un sociólogo en posición de observador omnisciente que se tiene además por el único individuo capaz de disipar la ilusión y de desvelar las realidades ocultas" (Boltanski 2016:42). Cuestión que se acentúa al abordar las relaciones de dominación a las que los actores se ven sometidos, pues "para explicar cómo y por qué se ven dominados los actores sin saberlo, la teoría ha de conceder una gran importancia a las ilusiones que les ciegan y recurrir al concepto de inconsciente. Una primera consecuencia de ello es que los actores se ven con frecuencia tratados como individuos engañados o aun sujetos a la condición de 'cultural dopes', por emplear aquí la expresión de Harold Garfinkel. Lo que ocurre, en particular, es que sus facultades críticas se ven subestimadas o ignoradas" (Boltanski 2014:40).

Apelación a Garginkel que no es casual, pues es una de las referencias a través de las cuales Boltanski procura sortear esta problemática, dando lugar a lo que él denomina un abordaje pragmático de la situación de los actores. Con vistas a realizar una "descripción fiel de las andanzas de los actores" (Boltanski 2014:46), pero donde esa descripción entraña ya una ruptura para con su punto de vista. Esto es lo que Boltanski tematiza como una "exterioridad simple", la cual remite a cómo la descripción sociológica requiere "haber tomado un punto de apoyo de carácter más o menos extraterritorial respecto de la sociedad que esté siendo objeto de la descripción" (Boltanski 2014:25). Por esta vía, se logra el distanciamiento que posibilita la ruptura para con la naturalización del estado actual de la sociedad, propia del punto de vista de la inmediatez.

En dicha descripción se basa la elaboración de las ciudades, tarea que ha de "asumir la conservación de la distancia, que es el elemento que subyace a la idea de la neutralidad axiológica" (Boltanski 
2016:9). Por lo que, desde el punto de vista sociológico, posicionado en la exterioridad simple, no se abre un juicio evaluativo sobre la realidad que se está describiendo, realidad que incluye a los juicios evaluativos producto del sentido moral de los actores.

Sobre esta base, puede detectarse el problema al que se enfrentan las perspectivas sociológicas que buscan practicar la crítica, en tanto "tienen la especificidad de contener toda una serie de juicios críticos sobre el orden social que el analista viene a asumir en su propio nombre, abandonando de ese modo la aspiración a la neutralidad" (Boltanski 2014:19). Cuestión que Boltanski tematiza como la apelación a una 'exterioridad compleja', con la cual la teoría metacrítica pretendería dotarse "de los medios precisos para realizar un juicio sobre el valor del orden social que esté siendo objeto de descripción" (Boltanski 2014:25). La exterioridad compleja no solo pone en cuestión la neutralidad axiomática, también conduce a una de esas objeciones a la crítica que se señalaron en la introducción: la dificultad de acoger el pluralismo.

En efecto, si la asimetría entre el punto de vista sociológico y el punto de vista de los actores puede conducir a que no se preste atención a las competencias de estos últimos, la exterioridad compleja puede llevar a que no se considere legítima más que la normatividad sostenida desde el punto de vista sociológico, reduciendo a la ilegitimidad, cuando no al simple error, toda otra orientación normativa. La sustentada por la sociología no sería, entonces, una normatividad entre otras posibles, sino la única válida, es decir, se la percibe "como si se tratara no de una concepción moral entre otras muchas, sino del ideal moral en sí" (Boltanski 2014:19).

Frente a esto Boltanski, en línea con su requerimiento de describir las andanzas de los actores, se plantea 'la exigencia metodológica inversa', tratando "de permanecer los más cerca posible de lo que dicen las personas, tomándonos en serio sus justificaciones, sus críticas y, ya en términos más generales, las exigencias morales que reivindican como propias" (Boltanski 2016:42). De esta manera él se plantea el problema del fundamento de la (meta)crítica, temática que atraviesa a la teoría de la acción comunicativa de Habermas, o a la lucha por el reconocimiento propuesta por Honneth. Como en esas perspectivas, Boltanski busca dotar a la crítica de un fundamento normativo, pero a diferencia de ellas, en lo que constituye una novedad de su planteo, se trata de una normatividad a la que se llega no por la vía teórica (analizando la racionalidad subyacente a los actos de habla, por caso), sino a través del estudio del sentido moral de los actores, en un uso sociológico de la noción 'normativo', que hunde sus raíces en la tradición durkheimiana. Es a través de su sociología de la crítica que procura dotar de un fundamento a la (meta)crítica realizada por la sociología. En suma, su empeño procede "con la vista puesta en abrir la posibilidad de un proyecto metacrítico susceptible de hallar fundamento en la recopilación y la explicación de las críticas desarrolladas por aquellos actores que se desenvuelven en las circunstancias propias de la vida cotidiana" (Boltanski 2014:49). De ello se sigue la tarea de conceptualizar y describir sociológicamente las críticas de los actores.

\section{La ciudad modelo}

Al abordar el sentido pragmático-moral de los actores, Boltanski coloca su foco en los fundamentos de sus juicios acerca del carácter (in)justo de una situación. Es decir, se problematizan los principios de justicia en base a los cuales se critica una situación como injusta, o bien se la confirma, al acordar con su carácter justo. La confirmación es, entonces, "un registro que posee [...] unas propiedades simétricamente inversas al de la crítica" (Boltanski 2014:120). Este sentido de la justicia es, a su vez, 
modelizado a través de la noción de ciudad (cité), por eso: "el concepto de ciudad está imbricado con la cuestión de la justicia. Trata de modelizar el tipo de operaciones a las que se entregan los actores [...] cuando se encuentran confrontados a un imperativo de justificación. Esta exigencia de justificación está indisociablemente ligada a la posibilidad de la crítica. La justificación es necesaria tanto para apoyar la crítica como para contestarla" (Boltanski y Chiapello 2010:64).

Dicha modelización parte de aseverar que este sentido común de la justicia se halla atrapado "en una tensión entre dos exigencias: la de ordenar a los seres humanos en aquellas situaciones en las que vienen a interactuar en función de su grandeza respectiva y la de respetar su igualdad fundamental, derivada del hecho de su pertenencia a una humanidad común" (Boltanski 2016:415). Es esta tensión la que torna necesaria la justificación, al plantearse la común humanidad que iguala a todos, estableciendo "una forma de equivalencia fundamental entre estos miembros que pertenecen todos con el mismo título a la humanidad" (Boltanski y Thévenot 1991:96). Al mismo tiempo que se plantea un ordenamiento que jerarquiza a los actores, estableciendo una desigualdad entre ellos, al menos entre dos grandes estados: el de grande y el de pequeño. La pertenencia a uno de estos estados no se encuentra fijada de una vez y para siempre, pues "el modelo debe suponer, para todos sus miembros, una potencia idéntica de acceso a todos los estados que nosotros designaremos por su común dignidad" (Boltanski y Thévenot 1991:98). En este marco, cada ciudad "se apoya en un principio de evaluación distinto que, al considerar a los seres bajo una determinada relación [...], permite establecer un orden entre ellos. Este principio recibe el nombre de principio de equivalencia" (Boltanski 2014:54, nota 29). Es decir, se plantea, por un lado, la equivalencia fundamental de la común humanidad y, por el otro, una equivalencia propia a cada ciudad, que permite tornar mensurable la "magnitud" de cada actor, su grandeza o pequeñez.

Boltanski considera que esta perspectiva puede acoger el pluralismo, pero sin por ello llevar a un pluralismo ilimitado, el cual, en su aceptar la co-existencia de una infinitud de principios de equivalencia, acarrearía un relativismo que deja sin fundamento a la crítica. En tanto la denuncia de injusticia, que la crítica entraña, apela a un principio de justicia, común a los actores en su situación. El conjunto acotado de ciudades y, consecuentemente, de sus principios de equivalencia, da lugar, entonces, a un 'pluralismo limitado', por el cual "podemos escapar de la alternativa entre un universalismo formal y un pluralismo ilimitado, al considerar la posibilidad de una pluralidad limitada de principios de equivalencia, los cuales pueden ser usados para dar soporte a críticas y acuerdos" (Boltanski y Thévenot 1999:365). Se trata de una cantidad acotada de ciudades (en De la justificación se describen seis ciudades, a las que en El nuevo espíritu del capitalismo se agrega una séptima, la ciudad por proyectos), cada una asentada en su principio de equivalencia. El complemento de lo cual es que cada uno de éstos entraña "un principio universal destinado a regir a la ciudad" (Boltanski y Thévenot 1991:87), es decir, tiene una pretensión de universalidad en esa ciudad.

En consecuencia, las ciudades son mutuamente incompatibles. A lo sumo, puede haber un compromiso entre los principios de dos ciudades distintas, como acontece, por caso, en los derechos del trabajador, en donde se reúnen elementos propios a la figura de ciudadano (ciudad cívica) con la figura de trabajador (ciudad industrial). Sin embargo, "el principio apuntalado por el compromiso permanece frágil, en tanto que él no puede ser relacionado a una forma de bien común constitutiva de una ciudad. El establecimiento de un compromiso no permite ordenar a las personas según una grandeza propia" (Boltanski y Thévenot 1991:338). Pues siempre se lo puede criticar movilizando uno de los principios de equivalencia en contra del otro denunciando, por caso, que el ingreso 
ciudadano es un 'subsidios para los vagos' que no producen, es decir, cuestionando el derecho (ciudadano) a partir de una justificación productivista (industrial). Punto en el que se evidencia uno de los aspectos de la crítica, aquél que Boltanski considera el más radical, el cual surge de la tensión entre principios de equivalencia incompatibles.

En esta "crítica radical", entonces, se "impugna la validez del bien reconocido en cada situación dada al oponerle otras formas de bien posibles" (Boltanski 2016:394), lo cual entraña un choque entre universales, particulares a cada ciudad. Choque que no puede resolverse apelando a un bien superior, pues "no existe una posición de sobrevuelo, exterior y superior a cada uno de los mundos" (Boltanski y Thévenot 1991:285). De esto se sigue la dificultad de cerrar la disputa que la crítica radical abre, pues "si quieren cerrarla, las personas involucradas deben trata de volver a una y solo una prueba" (Boltanski y Thévenot 1999:374). Pero ¿a cuál?, y, sobre todo, ¿cómo se llegaría a ella, si se tiene en cuenta que habría que abandonar uno de los principios de justicia en juego? Aun cuando se pueda llegar a un compromiso entre dos de tales principios y, así, "apaciguarse la crítica" (Boltanski y Thévenot 1991:335), no por ello se evita la fragilidad del compromiso.

En este punto se detecta uno de los problemas de la propuesta de Boltanski, cuyo combate del relativismo (complemento de su cuestionamiento al universalismo de la exterioridad compleja) se da por la vía de acotar los principios de justicia en juego (pluralismo limitado), de manera tal que aun la crítica radical apela a uno de entre éstos, por lo que ella se encontraría fundada... para el actor que la performa. Pero no así para el actor que busca confirmar la situación criticada y el principio de equivalencia que le subyace. ¿En qué se fundaría, entonces, la elección por un principio, por el otro o por el compromiso entre ambos (siempre que sean solo dos los principios en juego)? En el momento en que se pasa de la crítica, y su principio de justicia, a una pluralidad de actores cuyo sentido común moral entra en conflicto entre sí (pues perciben y aprecian de una manera diferente lo mismo, caso contrario no constituirían una pluralidad), la crítica queda sin fundamento común para orientar el curso de acción (confirmar o modificar la situación). Se puede explicar sociológicamente por qué un actor $\mathrm{X}$ defiende un principio, mientras que un actor $\mathrm{Y}$ defiende otro, pero ello no fundamenta esa orientación (más que para el propio actor), no hace válido un curso de acción por sobre el otro. Es decir, el relativismo se traslada a otro nivel. Si esto acontece ya en la crítica, entonces, frente a este problema, ¿cuál es la posición que adopta la sociología metacrítica? Temática sobre la que se volverá en la próxima sección.

\section{Intelectualismo y populismo en la crítica}

Antes de poder retomar la cuestión del pluralismo, con la objeción que contiene para la sociología crítica y el desafío que le presenta a la sociología pragmática de la crítica, es necesario enfocar la mirada en la otra objeción, aquella atinente a la asimetría entre la percepción de los actores y la de la sociología. Según Boltanski, la crítica (así como la confirmación) demanda el gesto "de tomar distancia respecto de la realidad o, si se quiere, de relativizarla" (Boltanski 2014:74), apoyándose para ello en una 'palanca exterior'. Pero, entonces, ¿no están adoptando los actores la exterioridad propia del punto de vista sociológico? En este punto, la manera como Boltanski rompe con la reducción de los actores a cultural dopes acarrea un deslizamiento hacia un 'intelectualismo' (como diría Bourdieu), entendido como la atribución a los actores de una relación con el mundo social que es propia del científico objetivante (y que, como tal, debería ser objetivada por el científico objetivante, antes que extendida a otros actores sociales). Sin esa palanca exterior los actores no podrían tomar distancia del mundo, naturalizando su estado actual, pero al tomarla, la manera en 
que la toman conduce a que ellos adquieran el rasgo definitorio del punto de vista sociológico, aquél que le permite cumplimentar 'su razón de ser'. Tal es el dilema al que conduce la propuesta de Boltanski: al cuestionar lo que Grignon y Passeron (en Lo culto y lo popular) Ilaman el 'miserabilismo' de la sociología crítica, esto es, su tendencia a reducir las prácticas de los actores a una reacción impuesta por la necesidad de lo social y, como tal, carentes de libertad (cuestionamiento con el que coincido), cae en (lo que para Grignon y Passeron es) el problema especularmente inverso del 'populismo', es decir, del festejo de las capacidades de los agentes, como si ellas no se viesen impactadas por la lógica de lo social y, en especial, por relaciones de dominación, afirmándose, en definitiva, "la superioridad de las costumbres y competencias dominadas" (Grignon y Passeron 1991:50).

En este contexto no sorprende que Boltanski sostenga la, por otra parte, bastante extraña afirmación según la cual "la posibilidad de introducir un cierto margen de maniobra en la realidad vendrá a depender también del grado en que los actores alcancen a acceder a un determinado conjunto de dispositivos prácticos y de herramientas cognitivas susceptibles de permitirles vencer su aislamiento [...]. Ahora bien, esas herramientas [...] son necesariamente un conjunto de constructos que adopta a su vez el punto de vista de la totalidad" (Boltanski 2014:64).

Extraña porque es el mismo punto de vista que, al comienzo de De la crítica (de donde está extraída la cita de marras), es señalado como propio de las teorías críticas de la dominación a las que cuestiona. En efecto, éstas "son teorías que asumen el punto de vista de la totalidad" (Boltanski 2014:15). Por esta vía se alcanzaría una suerte de coincidencia final entre el punto de vista de las teorías críticas y el de los actores, clásico problema sobre la relación entre teoría y práctica. Pero a esta coincidencia no se arriba por la vía miserabilista, con unos actores que han de abandonar su (falso) punto de vista, para hacer propio el de la teoría crítica, 'tomando consciencia' de su situación, al aprehenderla desde el punto de vista de la totalidad. Antes bien, se arriba por una vía populista, en tanto son los propios actores, en sus prácticas ordinarias, quienes se posicionan, frente al mundo social, con la exterioridad propia de ese punto de vista de la totalidad. Además del intelectualismo que esta postura contiene, cabe preguntarse: ¿cuál es, entonces, la 'razón de ser' del conocimiento sociológico, incluyendo aquél producido a través del modus operandi de la sociología pragmática de la crítica?

Esta deriva intelectualista y populista también puede detectarse en la modelización de las ciudades $y$, sobre todo, en las conclusiones que de ello extrae Boltanski. Cuestión que cristaliza, especialmente, en torno a la discusión sobre la ilegitimidad de los valores eugenésicos, motivo por el cual no pueden dar lugar a una ciudad. Para llegar a ese punto, cabe recordar que cada ciudad es una modelización del sentido común de justicia de los agentes, es decir, es una construcción teórica, que brinda "un modelo de justicia y no una descripción empírica de estados de realidad" (Boltanski y Chiapello 2010:460). Distinción importante pues, como el propio Boltanski, junto con Thévenot, lo señalan, no cabe confundir "Ios principios de explicación en uso en las ciencias sociales y los principios de interpretación puestos en acción por los actores, que las ciencias sociales aprehenden como objeto" (Boltanski y Thévenot 1991:23). Para decirlo con el consabido latiguillo de Bourdieu no cabe confundir "las cosas de la lógica con la lógica de las cosas" (Bourdieu 1990:286). En este marco podría llamar la atención que las ciudades se encuentran purificadas de toda norma social de carácter racista, patriarcalista o, en general, que fijen la subordinación de un grupo por lo que éste 'es'. ¿Acaso la descripción de la normatividad de los agentes no encuentra allí ningún atisbo de este tipo de normas? Parece difícil sostener que no hay actores sociales que consideren justo (según su 
sentido moral) que los hombres blancos alcancen estados a los que no tienen acceso los no-hombres o no-blancos. Esta problemática es justamente la que Boltanski y Thévenot buscan tematizar al abordar la imposibilidad de una ciudad eugenésica.

El carácter ilegítimo del orden eugenésico proviene de que los criterios que moviliza para evaluar el carácter (in)justo de una situación choca con dos de los axiomas (abordados en la sección anterior) sobre los que se construyen las ciudades: la común humanidad y la común dignidad. Es por ello que la concepción eugenésica "es completamente incompatible con las constricciones constitutivas de una ciudad" (Boltanski y Thévenot 1991:106), pues plantea unos "modos de evaluación, de calificación de la gente en una jerarquía de estados que, a diferencia de las grandezas, no son compatibles con una exigencia de común dignidad" (Boltanski y Thévenot 1991:104), por tanto, pretende dar lugar a "un orden sostenido por un valor ilegítimo" (Boltanski y Thévenot 1991:104). Base sobre la cual no puede edificarse una ciudad.

Lo anterior no implica, por supuesto, que ese valor no forme parte de la realidad social, antes bien, Boltanski es consciente de que la común humanidad, así como la común dignidad, pueden "entrar en conflicto con toda una serie de concepciones exclusivistas, nacionalistas o incluso racistas de lo colectivo" (Boltanski 2014:73). Lo que se establece es el carácter ilegítimo de dicho valor, pero ¿para cuál punto de vista?, ¿para el del actor que sostiene posturas asentadas en ese valor eugenésico?, esto es, ¿se trataría de un actor que pone en acción, en sus juicios, valores ilegítimos a sabiendas de lo que son? Parece difícil de sostener, a menos que se evalúe esa suerte de hipocresía del actor como el encubrimiento de una otra cosa, sus intereses económicos, por ejemplo. Pero ello llevaría a Boltanski a caer en el mismo tipo de argumento que cuestiona a la sociología crítica. ¿Acaso el actor sostiene ese valor sin percibir que es ilegítimo?, pero entonces, ¿es una suerte de cultural dope llevado a la ilegitimidad por su cultura racista?

Aun cuando quien escribe estas líneas (y muy probablemente quien las lee) considera regresivos e injustos los valores de carácter racista, no cabe universalizar esa evaluación, ni actuar como si tales valores se encontrasen ausentes de la realidad social. La sociología pragmática de la crítica se limita a tacharlos de ilegítimos, justificando así su no tratamiento. Pero su rechazo se sostiene en que en ellos "el axioma de la común humanidad no es verificado, ya que las dotaciones de las personas son irremediablemente desiguales al momento del nacimiento" (Boltanski y Thévenot 1991:104). Esto último explica por qué no se puede construir una ciudad en torno a esos valores, pero, a menos que se confunda la modelización teórica con la realidad social, de ello no se sigue automáticamente la universal ilegitimidad de tales valores. Por el contrario, señala más bien una limitación de las ciudades como herramental metódico para describir el sentido de justicia de los actores ordinarios, pues no puede dar cuenta de aquellos valores exclusivistas, los cuales son, quizás, los que más investigación, discusión y (meta)crítica ameritan. La otra posibilidad es elevar la común humanidad y la común dignidad no ya a axiomas de esa modelización teórica que es la ciudad, sino a una norma moral que ha de ser respetada por todos los actores, pero ¿no sería eso tornarlo un "ideal moral en sí", propio de la exterioridad compleja que Boltanski cuestiona?, es decir, ¿no sería tomar la postura de la sociología crítica que él rechaza?

Algo semejante sucede cuando Boltanski tematiza, lateralmente, la condición de los esclavos en la Roma antigua, cuya pertenencia a la común humanidad no era cuestionada, pues "no había nada que los distinguiera del resto de los seres humanos. [...] Pero se trataba en cualquier caso de unos seres humanos que lo eran (únicamente) por la carne, y no por la palabra" (Boltanski 2016:78). Esto 
es, lo eran únicamente en tanto hijos de otros seres humanos (estos últimos ¿también lo eran únicamente por la carne, o se reconocía su humanidad por la palabra?, Boltanski no toca la cuestión), pero sin que se produzca un "reconocimiento de su humanidad" (Boltanski 2016:72), por la palabra. Con ello no solo se introducen dos niveles de pertenencia a la común humanidad, que ya comienza a no ser tan común, también se está socavando la común dignidad.

En suma, para establecer la ilegitimidad de un conjunto de valores, que no es únicamente señalar que no son modelizables a través de las ciudades (lo cual podría ser, simplemente, una limitación de este modelo teórico), o bien Boltanski confunde la lógica de su teoría con la lógica de la realidad, o bien, eleva a ideal moral en sí los valores que están en los cimientos axiológicos de sus ciudades. Solo por estas vías puede dar el salto por el cual tornar a los valores incompatibles con las ciudades en ilegítimos para los actores, cuyas "andanzas" la sociología pragmática de la crítica procura seguir.

Esto es consecuencia del intelectualismo, que conduce a atribuirles a los agentes el axioma de la común humanidad, como si éste no fuese un pilar de las ciudades (cosas de la lógica), sino un pilar del sentido común de justicia de todos los actores (lógica de las cosas), junto con un populismo por el cual se expurga el sentido normativo de los actores de todo valor excluyente, como si éstos apreciasen como ilegítimos todos los valores que chocan con la comunidad humanidad, más aún, como si entendiesen que la común humanidad ha de incluir siempre a todos los individuos, es decir, que no hay grupos juzgados como no plenamente humanos (como postularía un punto de vista eugenésico $y$, en general, una concepción racista del mundo). Esto no solo entraña un problema para la "descripción empírica" que la sociología pragmática de la crítica pretende concretar, si es que consideramos plausible la presencia de actores con un sentido normativo racista, también atenta contra el fundamento que se procuraba obtener en dicho sentido normativo. Pues describir cómo un actor llega a justificar su crítica (o su confirmación) en un determinado principio de justicia, válido desde su punto de vista, no produce per se la justificación de esa crítica para otro punto de vista (y por más que quien escribe estas líneas no lo comparta, no es que en el discurso público estén ausentes las "denuncias de la injusticia" de que un no-blanco o un no-hombre alcancen ciertos estados). Aun cuando el modus operandi de la sociología pragmática de la crítica permitiese describir esto (para lo cual debería complementar su modelo de las ciudades con alguna construcción que le permita aprehender los valores contrarios a la común humanidad, sin proceder a descartarlos automáticamente como ilegítimos), no podría intervenir con su metacrítica, pues ¿en qué normatividad la fundaría?

Así, si se acepta que la normatividad de los actores puede incluir valores "ilegítimos", ello afecta no solo al herramental descriptivo, sino también a la pretensión de fundar la metacrítica en dicha normatividad. Más aún, si hay un conflicto entre dos principios de justicia, que según Boltanski son incompatibles entre sí dada su pretensión de universalidad, ¿̇la metacrítica alentaría el compromiso entre ambos?, ¿'se apoyaría en uno en detrimento del otro?, ¿en qué se fundamentaría cualesquiera de estas tomas de posición? En este punto se evidencian las limitaciones de este esfuerzo por fundar normativamente la crítica sociológica. Pues, si se quiere evitar elevar a ideales morales en sí a la axiomática de la ciudad, base sobre la cual luego evaluar la legitimidad o ilegitimidad de los valores, en una exterioridad compleja que disuelve el pluralismo, a la vez que, si se quiere evitar el intelectualismo de atribuir a los actores los mismos criterios que se autoplantea la tarea de modelización teórica, intelectualismo que no es más que el reverso de tratar a los actores como cultural dopes, entonces Boltanski no cuenta con un fundamento para su metacrítica. 
Sobre este telón de fondo puede percibirse como él plantea una compleja y muy interesante sociología cultural de la crítica (en el mismo sentido en que Benzecry habla de una "sociología cultural" [Benzecry 2012:10] y cuyo culturalismo postfenomenológico he cuestionado en Bourdieu y lo político), pero diluye la posibilidad de elaborar a la vez una sociología crítica de la cultura, incluyendo en dicha cultura a la normatividad de los actores, sea que ella pueda dar lugar a una ciudad o no (como en el caso de los valores eugenésicos). El desafío es, entonces, elaborar el modus operandi de una sociología crítica, sin dejar de tener en cuenta los cuestionamientos que Boltanski le realiza a la misma (vistos al inicio de este trabajo), pues dichos problemas no desaparecen solo porque la respuesta del propio Boltanski no sea satisfactoria. La preocupación por practicar, a la vez, una sociología crítica de la cultura podría parecer una cuestión menor, pero su relevancia se evidencia en el estudio que Boltanski y Chiapello le dedican al nuevo espíritu del capitalismo, a la crítica que éste produce (del espíritu anterior), a la posibilidad de que él sea hoy criticado.

\section{¿Crítica neoliberal o crítica del neoliberalismo?}

La parte central del argumento de Boltanski y Chiapello puede resumirse en que ellos estudian, en una misma investigación, dos críticas fundamentalmente distintas: una relativamente exitosa, otra que ha tendido a apagarse y por cuyo resurgimiento los autores apuestan. La primera de ellas es la crítica neoliberal de la cultura, específicamente la crítica que (aquello que los autores denominan como) el tercer espíritu del capitalismo (cuyos primeros atisbos pueden rastrearse en la década del 70 y su consolidación en los años 90) le dirige al segundo espíritu del capitalismo, predominante durante la Segunda Posguerra Mundial. En línea con el modus operandi de una sociología de la crítica, el objeto estudiado es la crítica realizada por ese tercer espíritu, al cual cabe calificar como neoliberal, es decir, se trata aquí de una sociología (cultural) de la crítica neoliberal al segundo espíritu del capitalismo. La otra es la crítica al neoliberalismo, la cual hace pie en "las formas históricas de la crítica del capitalismo" (Boltanski y Chiapello 2010:83). Punto en el cual ya no se trataría únicamente de una sociología de la crítica, sino también de una vía por la cual Boltanski y Chiapello plantean sus propias críticas, esto es, esbozan una crítica de la cultura neoliberal.

El conjunto de su argumento pivotea en torno a dichas formas históricas de la crítica del capitalismo, a las cuales agrupan en dos tipos, que recurren, cada una, a dos fuentes de indignación, base para la denuncia de una injusticia, es decir, para la crítica. Por un lado, la "crítica artística", la cual apela a la indignación para con un capitalismo fuente tanto de inautenticidad como de opresión de la autonomía, la libertad y la creatividad del individuo. Por el otro, la "crítica social", que recurre a la indignación frente al capitalismo por ser éste fuente tanto de miseria y desigualdad, como de un egoísmo contrario a las relaciones de solidaridad.

Ahora bien, Boltanski y Chiapello sostienen que la dinámica del espíritu del capitalismo "tiene a la crítica como motor" (Boltanski y Chiapello 2010:241), en tanto las transformaciones que llevan a la emergencia de la ciudad por proyectos, propia del tercer espíritu del capitalismo, son una respuesta a las críticas que se le realizan al (segundo espíritu del) capitalismo en los años 60 y 70 . Sobre esta base es que, a ellos, les parece "bastante evidente que la nueva gestión empresarial [de la ciudad por proyectos] trata de responder a las demandas de autenticidad y libertad, enarboladas históricamente de forma conjunta por lo que hemos denominado la 'crítica artística', dejando de lado las cuestiones del egoísmo y de las desigualdades, tradicionalmente asociadas a la 'crítica social'" (Boltanski y Chiapello 2010:149). 
Por esta vía, "oponiéndose al capitalismo social planificado y encuadrado por el Estado -considerado obsoleto, estrecho y coactivo- y adhiriéndose a la crítica artística (autonomía y creatividad), el nuevo espíritu del capitalismo toma progresivamente forma [...] y emprende la tarea de revalorizar el capitalismo" (Boltanski y Chiapello 2010:296). Punto en el que se evidencia cómo la crítica al capitalismo puede ser apropiada por éste, tornándose una crítica realizada por el capitalismo, movilizándola para revalorizarse.

El que ello lleve aparejado un crecimiento de la desigualdad y del egoísmo individualista no menoscaba la brillante tesis de Boltanski y Chiapello acerca de la capacidad del espíritu del capitalismo de dar respuesta a sus críticas, sin abandonar por ello su núcleo básico: ser capitalista. Antes bien, es aquí donde puede verse la riqueza y potencia de esta sociología de la crítica neoliberal (al capitalismo social planificado), la cual moviliza elementos de la crítica artística en su favor. Pero ¿y la crítica al capitalismo?, más aún, ¿y la sociología crítica del neoliberalismo? Sobre la primera de estas cuestiones, Boltanski y Chiapello cierran su investigación señalando la posibilidad de nuevas formas de la crítica, básicamente, el "renacimiento de la crítica social" (Boltanski y Chiapello 2010:443), por un lado con foco en la injusticia de la desigualdad producida por el neoliberalismo, recuperando así aquellos motivos de indignación frente al capitalismo que el neoliberalismo no volvió un motor de su propia dinámica. Por el otro, la recuperación de la crítica artística, con énfasis no tanto en la libertad (apropiada por el neoliberalismo), como en la cuestión de la autenticidad, la cual abre una vía para tematizar "los límites que sería necesario imponer a la mercantilización" (Boltanski y Chiapello 2010:591) de todos los aspectos de la vida. Éste es el camino que podría llevar a un relanzamiento de la crítica artística.

Ahora bien, ¿̇sobre cuál fundamento cabe asentar esta apuesta por la crítica al neoliberalismo, en lugar de apostar por la crítica neoliberal? Se puede explicar sociológicamente cómo determinados actores toman posición por una u otra (complementando la sociología de la crítica con un estudio de las trayectorias sociales de los actores y de su impacto sobre su sentido moral), pero ello no fundamenta a ninguna de las dos críticas (a lo sumo, las justifica para el propio actor que la produce, desde su punto de vista). Sin dudas, el espíritu del neoliberalismo conlleva una justificación de la desigualdad producida por el capitalismo, pero ¿basta que desde mi punto de vista eso sea injusto para tornar ilegítimo ese valor, al igual que se hacía con el eugenésico? Ello implicaría volver a apelar a la axiomática de las ciudades como punto de apoyo para una exterioridad compleja, como la que el propio Boltanski cuestiona. Además de que si fuese ilegítimo en este sentido, no podría dar lugar a la ciudad por proyectos, por el mismo motivo que no puede haber una ciudad eugenésica. Es decir, concuerdo con la orientación política que Boltanski y Chiapello plantean, pero el paso que dan para fundarla va en contra de la propia sociología pragmática de la crítica o, al menos, señala un silencio en la base de su edificio teórico: no hay elementos con los que justificar la orientación por un principio de justicia en lugar de otro (por los que subyacen a la crítica social, contra los de la ciudad por proyectos), aun cuando la temática "de la justificación" sea central a la propuesta de Boltanski.

Esto se traslada y agudiza en la segunda cuestión. Se traslada porque Boltanski plantea que la metacrítica sociológica se sustenta "en las críticas desarrolladas por los actores" (Boltanski 2014:62), por lo que si en estas últimas no hay elementos que justifiquen la orientación por un principio en detrimento del otro, ello también se traslada a la crítica desarrollada por la sociología. Se agudiza porque ahora esa orientación normativa no es parte del objeto estudiado (que puede incluir la indagación de cómo los actores hacen propio ese sentido común de justicia), sino que integra el propio modus operandis a través del cual se realiza la (meta)crítica sociológica. Por supuesto, se 
puede objetivar al sujeto objetivante para estudiar las condiciones sociales que llevan a Boltanski, o a quien escribe estas líneas, a oponerse a la crítica neoliberal, pero ello no funda una crítica sociológica del capitalismo. Así como tampoco permite tejer ese hilo normativo en su trama teórica (¿cuál es su estatuto conceptual?). Se trata de la misma temática que se evidenciaba al final del apartado anterior, por la cual su sociología cultural de la crítica (neoliberal) no puede ser, a la vez, una sociología crítica de la cultura (neoliberal), al caer en el mismo dilema que el propio Boltanski intenta evitar. Pues o bien vuelve a una determinada orientación política (la igualdad como crítica del espíritu del neoliberalismo) en un ideal moral en sí con el universalismo absolutista que ello implica, o bien acepta que esa puede ser una entre varias orientaciones posibles, todas igualmente válidas (como los dioses de los valores weberianos), en un pluralismo limitado de hecho (pues en una determinada coyuntura histórica no coexisten una infinidad de principios de equivalencia), pero que no por ello funda la apuesta por un principio de equivalencia contra otro. Por esta ventana entra el relativismo que Boltanski buscaba echar por la puerta.

\section{Conclusión: la ideología y su promesa utópica}

El recorrido anterior ha buscado, por un lado, dar cuenta de la compleja y potente sociología de la crítica que Boltanski propone como modus operandi a través del cual describir el sentido prácticomoral de los actores. Por el otro, hacer foco en los cuestionamientos que él le realiza a la sociología crítica, así como en los problemas a los que conduce el procurar sortearlos apelando a la normatividad de los actores como fundamento de la (meta)crítica sociológica. Sin embargo, puede detectarse, esbozada como en línea de puntos, una vía alternativa por la cual elaborar una sociología crítica, especialmente en la manera en que Boltanski y Chiapello tratan a la crítica artística y, en particular, a sus reclamos de libertad y autonomía, apropiados por el espíritu del neoliberalismo.

Éste último moviliza tales reclamos contra las regulaciones del capitalismo social, que garantizaban un piso de seguridad para los trabajadores, pero también limitaban su libertad de movimiento, al encerrarlos en burocracias rígidas. Así, la conquista de "la autonomía ha sido intercambiada por la seguridad abriendo la vía a un nuevo espíritu del capitalismo" (Boltanski y Chiapello 2010:294). Frente a ello, Boltanski y Chiapello buscan recuperar "la seguridad como factor de la liberación", es decir, sostienen que la seguridad es una condición para alcanzar esa libertad que la crítica artística demanda, pues "todo aquello que en la actualidad aumenta la seguridad y la estabilidad laborales de las personas, libera un margen de libertad" (Boltanski y Chiapello 2010:592). En esto se vislumbra no solo la referencia al principio de justicia al que apela el espíritu del neoliberalismo, para confirmarse y para criticar al espíritu anterior, sino que también se da un paso más, que consiste en "tomar en serio la exigencia de justicia contenida en la ciudad" (Boltanski y Chiapello 2010:488). Ya que si la tomamos en serio, podríamos aprehender sociológicamente que la ciudad por proyectos no cumple la libertad y autonomía que promete, que no puede cumplir su promesa aun cuando sea fundamental al espíritu del neoliberalismo. Pues promete la autonomía de un individuo aislado, suerte de nuevo Robinson Crusoe en su isla, aun cuando el estar "conectado" dentro de la "red" sea el elemento definitorio de la grandeza en esta ciudad. "El ascenso del individualismo es el último de los "grandes relatos'" (Boltanski y Chiapello 2010:650), que hace sentir aquí su peso, al ofrecer una autonomía frente a la rígida seguridad de las regulaciones colectivas, pero no frente a la red, cuyos nodos el individuo debe recorrer para mantenerse conectado, participando en proyectos. En definitiva, no se es libre en relación con las (nuevas) demandas del capitalismo, frente a las cuales este individuo 'autónomo' ya no cuenta con la protección de la organización colectiva (sindical y/o estatal). 
En este punto se evidencia como la autonomía neoliberal es una apariencia necesaria al contexto configurado por el espíritu del neoliberalismo. Necesaria en tanto base sobre la que se erige su crítica (al espíritu del capitalismo social), así como su confirmación, en definitiva, en tanto instancia central del principio de justicia al que apela y, consecuentemente, de su propia justificación. A la vez que es necesariamente producida por un espíritu del neoliberalismo que propugna una reindividualización de los actores, la cual no es más que el reverso de su des-colectivización (según argumenta Castel en El ascenso de las incertidumbres), es decir, propugna la producción de individuos 'autonomizados' de lo colectivo y sus marcos regulatorios. Pero se trata de una apariencia, en el sentido de que es una instancia nuclear del modo y la manera de la percepción de los actores, dentro de este específico contexto, esto es, de cómo a éstos se les aparece el mundo y juzgan la grandeza propia y ajena. Al mismo tiempo que, si nos 'tomamos en serio' esta exigencia de autonomía, entonces podemos explicar los procesos por los cuales ella no se cumple. Pues se trata (para decirlo de una manera relativamente simplificada) de la autonomía que la publicidad de Uber promete a los conductores: ser tu propio jefe. El 'silencio' de esa promesa, lo que ella no puede más que callar, es que también serán sus propios empleados. Unos que deberán trabajar en condiciones flexibilizadas al máximo y sin ninguna forma de protección colectiva (como el sindicato, que los peones de taxi sí tienen).

Al señalar el carácter de apariencia necesaria de esa autonomía se está indicando su dimensión ideológica, pero no en el sentido en que Boltanski, junto con Chiapello, entienden a la noción de 'ideología', al conceptualizarla como "un conjunto de creencias compartidas, inscritas en instituciones" (Boltanski y Chiapello 2010:33), sino dando un paso más, que recupera un elemento básico de cómo la entiende la tradición crítica. Con ello no se reduce a los actores a un estado de falsa consciencia o a meros cultural dopes, sino que se hace del introducirnos en la complejidad de un modo de percepción y de su producto (la configuración de sentido con la que así se dota al mundo), la vía por la cual alcanzar esa exterioridad (objetivante), intrínseca al conocimiento sociológico, según Boltanski. Senda por la cual romper con la implicación inmediata en la realidad, junto con la manera en que ésta se justifica, para dar cuenta de aquellos valores que "apaciguan la crítica" de los actores, sin por ello concretarse en la configuración de las relaciones sociales y que, por tanto, contribuyen a que se reproduzca una situación de injusticia (la heteronomía del conductor de Uber), según los propios criterios del principio de justicia que confirma esa situación. Manera de ver el mundo que no resulta evidente a los ojos de los actores, cumpliendo así con la 'razón de ser' de la sociología.

Este modo de operar sociológicamente tampoco implica reducir esa autonomía, y el sentido común de justicia en que se enraíza, únicamente a una ideología a ser (meta)criticada, para luego 'superarla'. Pues ese sentido común también contiene una promesa, que aún no ha sido cumplida, la de una autonomía y libertad no del individuo aislado, sino del individuo dentro de específicas condiciones sociales que, como tales, lo condicionan, en este caso, la red y los lazos que en ella se tejen. La autonomía y su justicia, centrales al espíritu del neoliberalismo, cumplen una función ideológica cuando "se comportan como si se hubieran realizado ya" (Adorno 2004:442), a la vez que contienen una promesa, cuyo cumplimiento no tiene lugar dentro de dicho espíritu y, más en general, dentro del capitalismo, es decir, entraña una dimensión utópica, que puede ser introducida en el mundo si pedimos lo imposible, más específicamente, lo que dentro de este capitalismo y su particular modo de percepción se nos aparece como impensable, porque es, en efecto, imposible... dentro del capitalismo. Porque su posibilidad concreta requiere la transformación de ese modo de ordenar lo social. 
Boltanski elabora un potente modus operandi para la descripción sociológica de materiales morales, en particular, para el estudio de la normatividad de los actores. Base sobre la cual puede construirse una interrogación de la dimensión ideológica y utópica potencialmente contenida en esos materiales morales. Paso que modifica el modus operandi, apuntando a la elaboración de una sociología crítica de la cultura, la cual no es solo la graphia del sentido de (in)justicia puesto en acto por los actores. Pues también entraña una logia de los procesos que producen y reproducen una situación de injusticia, incluyendo en ello los dispositivos que, al invisibilizar la injusticia (la heteronomía del conductor de Uber), la apuntalan para que perdure en el tiempo. Sea porque lleva a que se la vea con la apariencia de la justicia (la autonomía 'ganada' por ese conductor), sea porque lleva a que no se la vea, a que quede naturalizada, con la consecuencia de tornar impensable e imposible (para el punto de vista que no rompe con la implicación en esa naturalización) su transformación. Modus operandi para una sociología crítica que se pone como tarea hacer de su conocimiento, de esa logia, una instancia que contribuya a la transformación de la actual situación de injusticia, es decir, que busca contribuir a introducir la justicia en el mundo.

Ahora bien, este movimiento de la teoría se asemeja al del barón de Münchhausen cuando intenta salir del pozo en que está hundido tirándose de la coleta, pues se adentra en el material, en la normatividad de los actores, para por dicha vía alcanzar el exterior del que Boltanski habla. Ese movimiento dialéctico, sin embargo, no resuelve la cuestión de por qué apostar por la autonomía y la libertad, en lugar de hacerlo por alguna otra orientación. Es decir, no conduce a una 'exterioridad compleja'. El recorrido que el presente escrito ha realizado acoge los cuestionamientos que Boltanski le plantea al intento de dotar a la crítica de un fundamento en base a la normatividad (filosófica) de un ideal moral en sí, pero también señala que el problema así abierto no se resuelve apelando a la normatividad (sociológica) de los actores como único fundamento de la crítica sociológica. Por ello, quizás sea tiempo de dejar atrás ambos tipos de pretensiones normativas, procurando, en cambio, dotarla de un fundamento no normativo, avanzando por un camino que lleva hacia una teoría crítica reflexiva.

\section{Bibliografía}

Adorno, T. (2004). Obras completas. Tomo 8. Akal.

Benzecry, C. (2012). Hacia una nueva sociología cultural. UNQui editorial.

Boltanski, L. (2014). De la crítica. Compendio de sociología de la emancipación. Akal.

Boltanski, L. (2016). La condición fetal. Una sociología del engendramiento y del aborto. Akal.

Boltanski, L; Thévenot, L. (1991). De la justification. Les économies de la grandeur. Gallimard.

Boltanski, L; Thévenot, L. (1999) The sociology of critical capacity. European Journal of Social Theory 2(3), 359-377. https://doi.org/10.1177/136843199002003010

Boltanski, L; Chiapello, È. (2010). El nuevo espíritu del capitalismo. Akal.

Bourdieu, P. (1990). Sociología y cultura. Grijalbo.

Grignon, C; Passeron, J-C. (1991). Lo culto y lo popular. Miserabilismo y populismo en sociología y en literatura. Nueva Visión.

Recibido el 22 Sep 2020

Aceptado el 2 Nov 2020 